Old Dominion University ODU Digital Commons

Psychology Faculty Publications

Psychology

2014

\title{
Caffeinated Alcohol Use and Expectancies for Caffeine Versus Alcohol
}

Cathy Lau-Barraco

Old Dominion University

Ashley N. Linden

Old Dominion University

Follow this and additional works at: https://digitalcommons.odu.edu/psychology_fac_pubs

Part of the Psychiatric and Mental Health Commons, Psychology Commons, and the Substance Abuse and Addiction Commons

\section{Repository Citation}

Lau-Barraco, Cathy and Linden, Ashley N., "Caffeinated Alcohol Use and Expectancies for Caffeine Versus Alcohol" (2014).

Psychology Faculty Publications. 54.

https://digitalcommons.odu.edu/psychology_fac_pubs/54

\section{Original Publication Citation}

Lau-Barraco, C., \& Linden, A. N. (2014). Caffeinated alcohol use and expectancies for caffeine versus alcohol. Substance Use \& Misuse, 49(10), 1241-1249. doi:10.3109/10826084.2014.891619

This Article is brought to you for free and open access by the Psychology at ODU Digital Commons. It has been accepted for inclusion in Psychology Faculty Publications by an authorized administrator of ODU Digital Commons. For more information, please contact digitalcommons@odu.edu. 
Published in final edited form as:

Subst Use Misuse. 2014 August ; 49(10): 1241-1249. doi:10.3109/10826084.2014.891619.

\title{
Caffeinated Alcohol Use and Expectancies for Caffeine Versus Alcohol
}

\author{
Cathy Lau-Barraco and Ashley N. Linden \\ Department of Psychology, Old Dominion University, Norfolk, Virginia, USA
}

\begin{abstract}
Background-Caffeinated alcoholic beverage $(\mathrm{CAB})$ use is related to alcohol-related risk. Limited research has examined outcome expectancies and $\mathrm{CAB}$ consumption.

Objectives-This study tested the predictive utility of caffeine and alcohol expectancies in $\mathrm{CAB}$ use outcomes (i.e. quantity, frequency, and alcohol-related harms).

Methods-Participants were 419 (302 women) alcohol and caffeine users from a mid-sized urban university. Data collection occurred between August 2010 and December 2011. Participants completed measures of caffeine and alcohol expectancies, alcohol problems, alcohol use, and $\mathrm{CAB}$ use.

Results-Caffeine and alcohol expectancies contributed uniquely to approximately $12 \%$ of the variability in quantity, $8 \%$ in frequency, and $16 \%$ in problems. When examined separately, alcohol expectancies explained approximately $10 \%$ to $11 \%$ of the variance, whereas caffeine expectancies accounted for $6 \%$ of the variance in $\mathrm{CAB}$ use quantity. For $\mathrm{CAB}$ use frequency, alcohol and caffeine expectancies accounted for about $8 \%$ and $4 \%$, respectively. Alcohol expectancies accounted for $12 \%$ to $14 \%$ of variance, whereas caffeine expectancies accounted for $4 \%$ to $6 \%$ in alcohol-related harms.
\end{abstract}

Conclusions/Importance-The present study sought to address a gap in the literature regarding the contributions of expectancies in the prediction of $\mathrm{CAB}$ use. Our findings provide support for the predictive utility of both caffeine and alcohol expectancies in accounting for individual variability in $\mathrm{CAB}$ use but alcohol expectancies may exert greater impact on use patterns. Inclusion of both types of expectancies in larger theoretical frameworks may be beneficial in gaining a more complete and deeper conceptualization of this risky behavior.

\section{Keywords}

alcohol; caffeine; caffeinated alcohol; expectancies; risky drinking; college students

Copyright (@) 2014 Informa Healthcare USA, Inc.

Address correspondence to Cathy Lau-Barraco, Department of Psychology, Old Dominion University, Mills Godwin Building, Norfolk, VA 23529, USA; cbarraco@odu.edu.

Declaration of Interest The first author is supported by Career Development Award K01-AA018383 from the National Institute of Alcohol Abuse and Alcoholism. The authors report no other conflicts of interest. The authors alone are responsible for the content and writing of this paper. 
Caffeinated alcohol use has been growing in popularity among emerging adults. As much as one fourth to one half of college drinkers reported consuming caffeinated alco holic beverages (CAB) in the previous 30 days (Brache \& Stockwell, 2011; MacKillop et al., 2012; O'Brien, Mc-Coy, Rhodes, Wagoner, \& Wolfson, 2008). Lifetime use estimates have been found to be as high as 75\% (Berger, Fendrich, \& Fuhrmann, 2013). CAB may be either premixed with alcohol and caffeine (e.g. original versions of Four Loko and Sparks) or mixed by the user (e.g. vodka or Jagermeister mixed with Red Bull).

While users may perceive benefits to drinking $\mathrm{CAB}$ (e.g. greater intoxication, alertness; Jones, Barrie, \& Berry, 2012; Peacock, Bruno, \& Martin, 2013), emerging research suggests that the co-consumption of alcohol with caffeine may present greater risk to the individual than consuming alcohol alone. College student consumers of $\mathrm{CAB}$, either pre-premixed or self-mixed, drink alcohol in greater quantities and drink more frequently as compared to alcohol-only users (MacKillop et al., 2012; O'Brien et al., 2008; Thombs et al., 2010). Caffeine and alcohol co-administration has been associated with greater alcohol-related consequences (O'Brien et al., 2008) and intentions to drink under the influence (Thombs et al., 2010). Consumers of $\mathrm{CAB}$ have increased odds of engaging in risky sexual behavior and greater use of other substances (Snipes \& Benotsch, 2013). As the frequency of CAB use increases, so does a person's odds of experiencing negative outcomes or engaging in risky behaviors (Brache \& Stockwell, 2011). CAB use is perceived to be related to some harms that are unique to $\mathrm{CAB}$ versus alcohol including heart palpations, blackouts, and consuming greater amounts of alcohol than intended (Jones et al., 2012).

It is important to note that many of the studies focusing on $\mathrm{CAB}$ use and negative outcomes have been based on between group comparisons of $C A B$ versus non-CAB users. This has prompted some researchers to question whether the increased risk may be attributed to individual differences in risk-taking (e.g. Howland \& Rohsenow, 2013). While there is some support that $\mathrm{CAB}$ users report greater impulsivity and pleasure seeking than nonusers (e.g. Heinz, de Wit, Lilje, \& Kassel, 2013), the odds of engaging in risky behaviors or experiencing negative alcohol outcomes appear to increase as $\mathrm{CAB}$ use frequency increases, even after controlling for risk taking tendency and alcohol use (Brache \& Stockwell, 2011). Furthermore, of investigations employing within-subjects designs, two have provided support for lower alcohol consumption on $\mathrm{CAB}$ using compared to non-CAB using days (de Haan, de Haan, der Palen, Olivier, \& Verster, 2012; Woolsey, Waigandt, \& Beck, 2010). However, contrasting these findings, Price and colleagues (2010) found greater alcohol consumption on occasions when CABs are consumed. This emerging area of research on the unique risks of $\mathrm{CAB}$ use is mixed and clearly highlights the need for additional research. There does, though, appear to be preliminary evidence suggesting $\mathrm{CAB}$ use to be associated with greater negative consequences. Efforts to increase our understanding of $\mathrm{CAB}$ use by identifying relevant predictors may help guide eventual efforts to minimize the harms associated with its use.

Outcome expectancies for drug effects are a consistent predictor of substance use behavior. Drug outcome expectancies are beliefs about the behavioral effects of a substance that may be acquired by direct or vicarious learning (Maisto, Carey, \& Bradizza, 1999). From a social learning perspective, our expectations of the consequences of using a substance will 
influence the likelihood of us engaging in that particular behavior. The largest body of work on expectancy effects has focused on alcohol. Alcohol expectancies are well established as an important determinant of alcohol use outcomes (Goldman, Darkes, \& Del Boca, 1999). They have been found to predict concurrent and prospective drinking (Christiansen \& Goldman, 1983; Stacy, Newcomb, \& Bentler, 1991), as well as alcohol-related consequences (Blume, Lostutter, Schmaling, \& Marlatt, 2003). Expectancies predict age of drinking onset and development of problem drinking (Christiansen, Smith, Roehling, \& Goldman, 1989). Heavier drinkers report more positive alcohol expectancies than lighter drinkers (Fromme, Stroot, \& Kaplan, 1993). Further, alcohol expectancies serve as a partial mediator between other antecedents (e.g. family history of alcoholism) and alcohol use (Sher, Walitzer, Wood, \& Brent, 1991).

In addition to alcohol, the expectancy framework has been applied to other substances including caffeine. Generally, research indicates that expectation of positive effects from using caffeine predicts how often and how much someone consumes it (Heinz, Kassel, \& Smith, 2009; Huntley \& Juliano, 2012). For instance, the stronger the belief that using caffeine will result in withdrawal/dependence effects, energy/work enhancement, appetite suppression, social/mood enhancement, and physical performance enhancement, the greater is their caffeine consumption (Huntley \& Juliano, 2012). Further, having lower expectations of negative caffeine effects, such as anxiety/negative physical effects and sleep disturbance, have been shown to predict greater caffeine use and decreased desire to lower use or to cut down (Huntley \& Juliano, 2012). Finally, it has been found that stronger endorsement of the expected effects of caffeine, be it positive or negative, was positively related to greater reports of caffeine withdrawal symptoms, dependence symptoms, cessation difficulty, and perceived addiction (Heinz et al., 2009). Overall, caffeine expectancies have been shown to relate to greater severity of caffeine use.

Given the salience of caffeine and alcohol expectancies in the use of each respective substance, it is possible that they both could contribute uniquely to our understanding of CAB consumption. Caffeinated alcoholic drinks combine two of the most widely and readily available substances, thus, they offer a unique opportunity to examine such associations. There exist only a handful of survey studies that focused specifically on the relationship between self-report expectancy endorsement and CAB consumption. Two investigations, examining caffeine expectancies in particular, found that $\mathrm{CAB}$ drinkers had stronger beliefs regarding caffeine's effect on social or mood enhancement (Huntley \& Juliano, 2012) and that $\mathrm{CAB}$ quantity is positively related to caffeine expectancies of withdrawal symptoms (e.g. feeling nauseous if do not drink caffeine regularly; Heinz et al., 2009). Prior research has not examined the distinct role of alcohol expectancies or the joint contributions of caffeine and alcohol expectancies in accounting for individual variability in $\mathrm{CAB}$ consumption. To our knowledge, there has been only one previous study that investigated CAB use in connection with both types of expectancies. This study identified four latent classes of CAB users (Lau-Barraco, Milletich, \& Linden, 2014). Findings indicated differential expectancy endorsement based on use profiles. Generally, those in the Low CAB use profile group endorsed weaker positive alcohol expectancies, whereas those in the High $\mathrm{CAB}$ class endorsed stronger withdrawal symptoms of caffeine expectancies. These results 
suggest that there may be meaningful differences between various types of CAB users and their endorsement of caffeine and alcohol expectancies.

Considering existing evidence, it is possible that the expected effects specific to caffeine or alcohol may account differentially for CAB use behavior. Previous research has not examined the unique and relative contributions of caffeine versus alcohol expectancies. Investigation of these relationships could offer insight into substance-specific and drug combination expectancies. Findings also may inform the inclusion of caffeine and alcohol expectancies into larger theoretical frameworks of CAB use and the development of more complete conceptual models of use. Consequently, the present study aimed to (1) test the predictive utility of caffeine and alcohol expectancies in $\mathrm{CAB}$ use outcomes including $\mathrm{CAB}$ use quantity, use frequency, and alcohol-related problems and (2) investigate the incremental influence of alcohol versus caffeine expectancies in explaining CAB use. It was hypothesized that both caffeine and alcohol expectancies would contribute significantly and uniquely to the prediction of $\mathrm{CAB}$ outcomes.

\section{METHOD}

\section{Participants and Procedure}

Participants were 419 (302 women) college student drinkers. Participants were recruited from an undergraduate psychology research pool at a mid-size east coast university. Data collection occurred between August 2010 and December 2011. Participants earned course credit as compensation for their participation. To be eligible, participants must have been (1) between the ages of 18 to 25, (2) reported consuming at least one alcoholic beverage during a typical week, and (3) reported consuming at least one caffeinated beverage during a typical week. The average age of the sample was $19.82(S D=1.71)$ years. Approximately 59\% of participants identified their racial group as Caucasian, 25.8\% as African American, 6.2\% as Asian, $3.3 \%$ as Hispanic, and $5.7 \%$ were self-identified as "other." Class standing of participants was $25.2 \%$ freshmen, $26.8 \%$ sophomores, $21.5 \%$ juniors, and $20.5 \%$ seniors. On average, the sample reported consuming $11.36(S D=8.92)$ standard alcoholic drinks per week.

Data were collected in small groups. Following informed consent, participants were provided with a packet of self-report questionnaires that took approximately 1 hour to complete. The present study was approved by the university's college committee on human subjects research prior to data collection and followed APA guidelines (APA, 2002).

\section{Measures}

Alcohol Expectancies-The Comprehensive Effects of Alcohol (CEOA; Fromme et al., 1993) assesses positive and negative alcohol expectancies. The CEOA consists of 38 items with responses ranging from 1 (disagree) to 4 (agree). The CEOA has four positive and three negative subscales. Positive subscales include: (1) sociability (e.g. "I would act sociable;" $a=.90)$, (2) tension reduction (e.g. "I would feel calm;" $a=.80$ ), (3) liquid courage (e.g. "I would feel courageous;" $a=.88$ ), and (4) sexuality (e.g. "I would enjoy sex more;" $a=.83$ ). Negative subscales include: (1) cognitive and behavioral impairment (e.g. 
"I would have difficulty thinking," $a=.86$ ), (2) risk and aggression (e.g. "I would be loud, boisterous, or noisy;" $a=.86$ ), and (3) self-perception (e.g. "I would feel self-critical;" $\alpha=$. 77). Overall, internal consistency was $a=.95$.

Caffeine Expectancies-The Caffeine Expectancy Questionnaire (CEQ; Heinz et al., 2009) was used to measure caffeine expectancies. The CEQ consists of 37 items with response options ranging from 1 (strongly disagree) to 4 (strongly agree). The CEQ provides four subscales: positive effects (e.g. "I pay attention more efficiently;" $a=.83$ ), acute negative effects (e.g. "Drinking caffeine makes me anxious;" $a=.88$ ), withdrawal symptoms (e.g. "The more I drink, the more addicted I become;" $a=.92$ ), and mood effects (e.g. "Drinking caffeine helps me feel more carefree;" $a=.82$ ). Internal consistency for the CEQ was $a=.93$.

Alcohol, Caffeine, and CAB Use-Alcohol and CAB consumption were each measured using the Daily Drinking Questionnaire (DDQ; Collins, Parks, \& Marlatt, 1985).

Participants reported on their consumption of (1) non-CAB and (2) CAB. They indicated the number of drinks typically consumed for each day of the week averaged over the past 3 months. As measures of $\mathrm{CAB}$ use or alcohol-only use, typical weekly drinking quantity was calculated by summing the drinks reported for each day of the week. The score for CAB drinking frequency was calculated by adding the number of days drinking occurs in a typical week.

Alcohol-Related Problems-The Young Adult Alcohol Consequences Questionnaire (YAACQ; Read, Kahler, Strong, \& Colder, 2006) assessed alcohol-related problems. The YAACQ is a 48-item self-report instrument that measures problems experienced in the past 12 months with yes or no response options (e.g. "I have become rude, obnoxious, or insulting after drinking"). The scale is calculated by summing the number of positive endorsements with higher scores indicating a greater likelihood of experiencing alcoholrelated problems. In this study, internal consistency was $a=.93$.

\section{RESULTS}

Prior to conducting analyses, data were cleaned and outliers were addressed. To correct for skewness in $\mathrm{CAB}$ use quantity and frequency, variables were transformed by taking their square roots. Hierarchical multiple regression analyses were used to examine the unique predictive utility of caffeine and alcohol expectancies in accounting for (1) CAB use quantity, (2) CAB use frequency, and (3) alcohol-related problems. For each outcome, two sets of regressions were conducted in which we varied the order of entry of alcohol (CEOA) and caffeine (CEQ) expectancies. In each regression, gender was entered at Step 1 to account for any differences in drinking behavior of men and women. Further, typical alcohol consumption was always entered as a predictor in Step 2 as a control variable. In our original set of analyses, caffeine use was entered in Step 3 as a control variable. However, because caffeine consumption did not account for significant variance in the model, it was excluded for parsimony. We applied the Bonferroni correction to control for Type I error. For each outcome, the adjusted alpha criterion was $p<.025$. Descriptive statistics and intercorrelations among study variables are presented in Table 1. 


\section{CAB Use Quantity}

When the CEOA subscales were entered first in Step 3, CEOA accounted for 10.8\% of the variance and CEQ accounted for $5.7 \%$ of the variance in $\mathrm{CAB}$ use quantity. Overall $R^{2}$ was . 161. With regard to specific CEOA subscales, greater cognitive and behavioral impairments alcohol expectancies were related to less $\mathrm{CAB}$ use quantity. Greater negative self-perception alcohol expectancies were related to greater $\mathrm{CAB}$ use. No CEQ subscales were associated with $\mathrm{CAB}$ use quantity.

When the CEQ was entered first, the CEQ accounted for $6.2 \%$ of the variance and the CEOA accounted for $10.2 \%$ of the variance in CAB use quantity. The resulting overall $R^{2}$ was .161. Greater caffeine withdrawal symptom expectancies were associated with greater $\mathrm{CAB}$ use quantity. Further, greater cognitive and behavioral impairment and self-perception alcohol expectancies were associated with $\mathrm{CAB}$ use quantity. See Table 2.

CAB Use Frequency-When the CEOA subscales were entered first in Step 3, CEOA accounted for $8.1 \%$ of the variance and the CEQ accounted for $4.2 \%$ of the variance in CAB use frequency. However, the variance accounted for by CEQ was no longer significant $(p=$. 04) following the Bonferroni correction. The resulting overall $R^{2}$ was .104. Regarding CEOA subscales, greater cognitive and behavioral impairment alcohol expectancies were related to less frequent $\mathrm{CAB}$ use. Greater self-perception alcohol expectancies were related to greater $\mathrm{CAB}$ use. No $\mathrm{CEQ}$ subscales were associated with $\mathrm{CAB}$ use frequency.

When the CEQ was entered first, the CEQ accounted for $4 \%$ of the variance and the CEOA accounted for $8.3 \%$ of the variance in CAB use frequency. The overall $R^{2}$ was .104 . Greater caffeine withdrawal symptom expectancies were associated with greater CAB use frequency. Further, greater cognitive and behavioral impairment and self-perception alcohol expectancies were associated with CAB use frequency. See Table 3.

Alcohol-Related Problems-When the CEOA subscales were entered first, CEOA accounted for $13.8 \%$ of the variance and the CEQ accounted for $4.2 \%$ of the variance in alcohol-related problems. The resulting overall $R^{2}$ was .513. Greater scores on both the risk and aggression and self-perception CEOA subscales were positively associated with alcohol-related problems. Greater CEQ mood effects were negatively related to alcoholrelated problems.

When the CEQ was entered first, the CEQ and the CEOA accounted for $6.2 \%$ and $11.8 \%$ of the variance in alcohol-related problems, respectively. The overall $R^{2}$ was .513 . Greater caffeine mood effect expectancies were associated with fewer alcohol-related problems. Further, greater acute negative caffeine expectancies were related to greater alcohol-related problems. Stronger CEOA risk and aggression and self-perception alcohol expectancies were associated with greater alcohol-related problems. See Table 4.

\section{DISCUSSION}

The present investigation sought to gain greater insight into factors predicting caffeinated alcohol use among young adults as these risky beverages are growing in popularity. 
Particularly, we were interested in examining the unique and joint contributions of caffeine and alcohol expectancies on $\mathrm{CAB}$ use in a sample of college drinkers. A large body of research supports outcome expectancies to be a consistent and strong predictor of substance use behavior. Efforts to establish associations between caffeine and alcohol expectancies in predicting $\mathrm{CAB}$ use may shed light into our conceptualization and prevention of such risky drinking practices. Overall, the variability accounted for across outcomes, caffeine and alcohol expectancies contributed uniquely to about $12 \%$ in quantity, $8 \%$ in frequency, and $16 \%$ in problems. Further, analyses indicated that our model, including gender and typical alcohol use as controls, accounted for approximately $16 \%$ of the variance in $\mathrm{CAB}$ use quantity and $10 \%$ in $\mathrm{CAB}$ use frequency. A finding of particular interest is that we were able to account for $51 \%$ of the variability in alcohol-related harms by including only four variables in our model.

When caffeine expectancies and alcohol expectancies were examined separately, findings revealed that each type of expectancy contributed uniquely to most $\mathrm{CAB}$ outcomes. In particular, regarding $\mathrm{CAB}$ use quantity, alcohol expectancies explained approximately $10 \%$ to $11 \%$ of the variance while caffeine expectancies accounted for $6 \%$ of the variance in use quantity. For $\mathrm{CAB}$ use frequency, alcohol and caffeine expectancies accounted for about $8 \%$ and $4 \%$, respectively, regardless of entry order. However, in the model where alcohol expectancies were entered first, the addition of caffeine expectancies was no longer significant following Type I error correction. Finally, alcohol expectancies accounted for $12 \%$ to $14 \%$ of variance, whereas caffeine expectancies accounted for $4 \%$ to $6 \%$ depending on the order in alcohol-related harms. Thus, both caffeine and alcohol expectancies contributed meaningfully to the prediction of most CAB outcomes. However, alcohol expectancies appear to be a stronger, more consistent predictor and account for greater incremental variance than caffeine expectancies.

Our findings advance existing research by demonstrating that the consumption of this unique cocktail may be accounted for by the user's beliefs regarding the individual effects of caffeine and alcohol. Through social learning, expectancies are acquired and those cognitive representations of the outcomes of the substance use are activated subsequently in drinking relevant contexts to influence behavior (Goldman, 2002). Given this, it may be that when individuals are in $\mathrm{CAB}$-use contexts, acquired expectations of the behavioral effects of caffeine and alcohol are both activated, and thereby, leading to a decision to consume the beverage. Consequently, expectancies of caffeine and alcohol may serve as underlying mechanisms of risk and could explain relationships found in previous work related to $\mathrm{CAB}$ use. For example, Heinz and colleagues (2013) found using a balanced placebo design that some of the effects of consuming CAB (e.g., inattention) are partially due to one's expectancies. Others have found that the expectation of receiving caffeine and alcohol led to poorer psychomotor performance if they expected impairment from the combined substances (Fillmore \& Vogel-Sprott, 1995) or if they expected caffeine to counteract alcohol impairment (Fillmore, Roach, \& Rice, 2002). These studies suggest that the influence of $\mathrm{CAB}$ use on subjective intoxication is through one's beliefs regarding the behavioral consequences of those substances. 
While the present study focused on alcohol and caffeine expectancies in general, expectancies related to the specific alcoholic beverage may also be important to consider. Alcohol expectancies have been shown to differ depending on the alcohol type. Findings have shown, for example, that expectations for beer are more positive as compared to liquor while wine is perceive to be less risky than beer and liquor (Pedersen, Neighbors, \& Larimer, 2010). Thus, in addition to learning about the role of caffeine versus alcohol expectancies in $\mathrm{CAB}$ use, it may be equally useful to learn about expectancies of the substances combined. Researchers have only very recently begun to focus on CAB-specific expectancies (MacKillop et al., 2012; Mallett, Marzell, Scaglione, Hultgren, \& Turrisi, 2013; Varvil-Weld, Marzell, Turrisi, \& Mallett, 2013). Reflecting the infancy of this area of research, the three studies that have examined $\mathrm{CAB}$ all used different measures of $\mathrm{CAB}$ expectancies. The most psychometrically rigorous of the three studies, MacKillop and colleagues (2012) developed a 9-item CAB expectancy measure with two subscales: "intoxication enhancement" and "avoid negative consequences." However, only the intoxication enhancement subscale predicted $\mathrm{CAB}$ use frequency. Its association to $\mathrm{CAB}$ use quantity is unknown as this was not examined by the authors. In the other two investigations, $\mathrm{CAB}$ expectancies were measured using a 3-item or 4-item instrument (Mallett et al., 2013; Varvil-Weld et al., 2013). Generally, these studies found that empirically derived profiles characterized by higher $\mathrm{CAB}$ use were associated with greater endorsement of $\mathrm{CAB}$ expectancies (e.g. "I can consume more alcohol when I choose to combine alcohol and energy drinks"). While these findings are promising and suggest that the expected effects specific to combining caffeine and alcohol are relevant, additional research into developing a psychometrically sound $\mathrm{CAB}$ expectancy measure that sample the entire domain of possible $\mathrm{CAB}$ expectancies is needed. Consideration of $\mathrm{CAB}$-specific expectancies, as well as alcohol and caffeine expectancies, in future models of $\mathrm{CAB}$ use could provide a more comprehensive understanding of factors that contribute to the development and maintenance of this risky behavior.

Given the growing popularity and risks associated with caffeinated alcoholic drinks on college campuses, prevention efforts to address this issue are needed before these students go on to develop more serious problems. A clinical implication of the present study is that outcome expectancies may be a viable or suitable vehicle through which to reduce the harms associated with alcohol consumption for vulnerable college drinkers who use $\mathrm{CAB}$. In the present study, we were able to account for over half of the variability in alcohol-related harms by including caffeine expectancies and alcohol expectancies in the model while controlling for gender and general alcohol use. The harm reduction model of substance use (Marlatt, 1998), whereby the focus is on minimizing harms and risky behaviors associated with use instead of specific drinking goals (e.g. abstinence), has been growing in popularity across colleges and universities (Dimeff, Baer, Kivlahan, \& Marlatt, 1999). In light of the current findings, efforts to reduce harms associated with college drinking among those who consume $\mathrm{CAB}$ could focus on expectancies specifically. Expectancies have been targets of alcohol interventions among moderate to heavy college drinkers. These "expectancy challenges" have been shown to be successful in modifying alcohol expectancy processes with corresponding changes in subsequent drinking (Lau-Barraco \& Dunn, 2008). Similar 
interventions may be tailored to those students who are also consuming $\mathrm{CAB}$ and that specifically address their expectations of caffeine, alcohol, and $\mathrm{CAB}$ consumption.

Our findings should be interpreted in light of several limitations. This study uses a crosssectional design that prevents us from making causal inferences. It is possible that $\mathrm{CAB}$ use predicts expectancies rather than expectancies predicting use. Future research would benefit from longitudinal examinations of the relationships between expectancies, $\mathrm{CAB}$ use, and alcohol-related problems. Relatedly, our study did not assess the role of CAB-specific expectancies as that was not the primary aim of the present study and also such an instrument was not yet available at the time of data collection for the present study. Future research would benefit from examining the unique role of $\mathrm{CAB}$ expectancies while also considering caffeine and alcohol expectancies. Another study limitation is that our assessment of various substance use (i.e. caffeine, alcohol, and caffeinated alcohol) was based on self-reports, which may be susceptible to recall bias or social desirability effects. However, self-reports of alcohol consumption have been shown to be reliable and valid (Del Boca \& Darkes, 2003). Related to the issue of assessment, future research would benefit from a clear and consistent operational definition of $\mathrm{CAB}$ use. For example, definitions have varied with defining $\mathrm{CAB}$ as "premixed or ad hoc CAB" (e.g. MacKillop et al., 2012) or simply as "caffeinated alcohol beverages" (e.g. Heinz et al., 2009) while others refer to it as "energy drinks mixed with alcohol" (e.g. O'Brien et al., 2008). Thus, a more consistent definition and reporting of those definitions clearly may provide greater clarity and facilitate comparison across investigations. Finally, another limitation is that our sample was fairly homogeneous, consisting of young adult college students who were women (72\%) and primarily Caucasian (59\%) or African-American (26\%). Therefore, findings may not be generalizable to non-student young adults, men, or individuals of other ethnicities. Future research may benefit from the inclusion of a more diverse sample.

The present study sought to address a gap in the literature regarding the contributions of expectancies in the prediction of $\mathrm{CAB}$ use. Our findings provide support for the predictive utility of both caffeine and alcohol expectancies in accounting for individual variability in $\mathrm{CAB}$ consumption and related harms. We also found that alcohol expectancies over caffeine expectancies may exert greater impact on $\mathrm{CAB}$ use patterns. Inclusion of both types of expectancies in larger theoretical frameworks may be beneficial in gaining a more complete and deeper conceptualization of this risky behavior.

\section{THE AUTHORS}

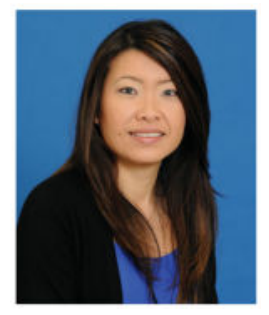

Cathy Lau-Barraco, Ph.D., is an Assistant Professor in the Department of Psychology at Old Dominion University. Her research focuses on psychosocial determinants and 
consequences of alcohol use and brief interventions with at-risk populations. She is currently the Principal Investigator of an Early Career (K01) Award from the National Institute of Alcohol Abuse and Alcoholism that is focused on evaluating a brief drinking intervention for nonstudent young adults.

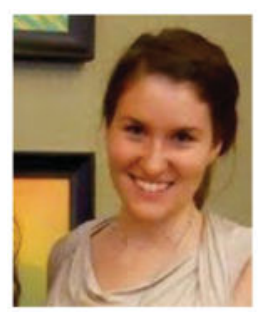

Ashley N. Linden, M.S. is a doctoral candidate in the Applied Experimental Psychology program at Old Dominion University. Her primary research interests are in psychosocial risk factors associated with alcohol use and caffeinated alcohol use among young adults.

\section{GLOSSARY}

Caffeinated

alcohol

Expectancies
Self-mixed beverages that contain both caffeine (e.g. Red Bull) and alcohol (e.g. vodka).

Beliefs about the effects of a substance, such as caffeine or alcohol.

\section{REFERENCES}

American Psychological Association. Ethical principles of psychologists and code of conduct. American Psychologist. 2002; 57:1060-1073. [PubMed: 12613157]

Berger L, Fendrich M, Fuhrmann D. Alcohol mixed energy drinks: Are there associated negative consequences beyond hazardous drinking in college students? Addictive Behaviors. 2013; 38:24282432. [PubMed: 23685329]

Blume AW, Lostutter TW, Schmaling KB, Marlatt GA. Beliefs about drinking behavior predicting drinking consequences. Journal of Psychoactive Drugs. 2003; 35:395-399. [PubMed: 14621140]

Brache K, Stockwell T. Drinking patterns and risk behaviors associated with combined alcohol and energy drink consumption in college drinkers. Addictive Behaviors. 2011; 36:1133-1140. [PubMed: 21840130]

Christiansen BA, Goldman MS. Alcohol-related expectancies versus demographic/background variables in the prediction of adolescent drinking. Journal of Consulting and Clinical Psychology. 1983; 51:249-257. [PubMed: 6841769]

Christiansen BA, Smith GT, Roehling PV, Goldman MS. Using alcohol expectancies to predict adolescent drinking behavior after one year. Journal of Consulting and Clinical Psychology. 1989; 57:93-99. [PubMed: 2925979]

Collins RL, Parks GA, Marlatt GA. Social determinants of alcohol consumption: The effects of social interaction and model status on the self- administration of alcohol. Journal of Consulting and Clinical Psychology. 1985; 53:189-200. [PubMed: 3998247]

de Haan L, de Haan HA, van der Palen HA, Olivier B, Verster JC. Effects of consuming alcohol mixed with energy drinks versus consuming alcohol only on overall alcohol consumption and negative alcohol-related consequences. International Journal of General Medicine. 2012; 5:953-960. [PubMed: 23204859]

Del Boca FK, Darkes J. The validity of self-reports of alcohol consumption: State of the science and challenges for research. Addiction. 2003; 98(Suppl 2):1-12. [PubMed: 14984237] 
Dimeff, LA.; Baer, JS.; Kivlahan, DR.; Marlatt, GA. Brief Alcohol Screening and Intervention for College Students (BASICS): A harm reduction approach. Guilford Press; New York, NY: 1999.

Fillmore MT, Roach EL, Rice JT. Does caffeine counteract alcohol-induced impairment? The ironic effects of expectancy. Journal of Studies on Alcohol. 2002; 63:745-754. [PubMed: 12529075]

Fillmore MT, Vogel-Sprott M. Behavioral effects of combining alcohol and caffeine: Contribution of drug-related expectancies. Experimental and Clinical Psychopharmacology. 1995; 3:33-38.

Fromme K, Stroot EA, Kaplan D. Comprehensive effects of alcohol: Development and psychometric assessment of a new expectancy questionnaire. Psychological Assessment. 1993; 5:19-26.

Goldman MS. Expectancy and risk for alcoholism: The unfortunate exploitation of a fundamental characteristic of neurobehavioral adaptation. Alcoholism: Clinical and Experimental Research. 2002; 26:737-746.

Goldman, MS.; Darkes, J.; Del Boca, FK. Expectancy mediation of biopsychosocial risk for alcohol use and alcoholism. In: Kirsch, I., editor. How expectancies shape experience. American Psychological Association; Washington, DC: 1999. p. 233-262.

Heinz AJ, de Wit H, Lilje TC, Kassel JD. The combined effects of alcohol, caffeine, and expectancies on subjective experience, impulsivity, and risk-taking. Experimental and Clinical Psychopharmacology. 2013; 21:222-234. [PubMed: 23750693]

Heinz AJ, Kassel JD, Smith EV. Caffeine expectancy: Instrument development in the Rasch measurement framework. Psychology of Addictive Behaviors. 2009; 23:500-511. [PubMed: 19769434]

Howland J, Rohsenow DJ. Risks of energy drinks mixed with alcohol. Journal of the American Medical Association. 2013; 309:245-246. [PubMed: 23330172]

Huntley ED, Juliano LM. Caffeine Expectancy Questionnaire (CaffEQ): Construction, psychometric properties, and associations with caffeine use, caffeine dependence, and other related variables. Psychological Assessment. 2012; 24:592-607. [PubMed: 22149323]

Jones SD, Barrie L, Berry N. Why (not) alcohol energy drinks? A qualitative study with Australian university students. Drug and Alcohol Review. 2012; 31:281-287. [PubMed: 21605204]

Lau-Barraco C, Dunn ME. Evaluation of a single-session expectancy challenge intervention to reduce alcohol use among college students. Psychology of Addictive Behaviors. 2008; 22:168-175. [PubMed: 18540714]

Lau-Barraco C, Milletich RJ, Linden AN. Caffeinated alcohol consumption profiles and associations with use severity and outcome expectancies. Addictive Behaviors. 2014; 39:308-315. [PubMed: 24210683]

MacKillop J, Howland J, Rohsenow DJ, Few LR, Am-lung MT, Metrik J, Calise TV. Initial development of a measure of expectancies for combinations of alcohol and caffeine: The Caffeine + Alcohol Combined Questionnaire (CACEQ). Experimental and Clinical Psychopharmacology. 2012; 20:466-472. [PubMed: 23230858]

Maisto, SA.; Carey, KB.; Bradizza, CM. Social learning theory. In: Blane, HT.; Leonard, KE., editors. Psychological theories of drinking and alcoholism. Guilford Press; New York: 1999. p. 106-163.

Mallett KA, Marzell M, Scaglione N, Hultgren B, Turrisi R. Are all alcohol and energy drink users the same? Examining individual variation in relation to alcohol mixed with energy drink use, risky drinking, and consequences. Psychology of Addictive Behaviors. 2013 [Epub ahead of print].

Marlatt, GA., editor. Harm reduction: Pragmatic strategies for managing high-risk behaviors. Guilford Press; New York, NY: 1998.

O'Brien MC, McCoy TP, Rhodes SD, Wagoner A, Wolfson M. Caffeinated cocktails: Energy drink consumption, high-risk drinking, and alcohol-related consequences among college students. Academic Emergency Medicine. 2008; 15:453-460. [PubMed: 18439201]

Peacock A, Bruno R, Martin FH. Patterns of use and motivations for consuming alcohol mixed with energy drinks. Psychology of Addictive Behaviors. 2013; 27:202-206. [PubMed: 22985055]

Pedersen ER, Neighbors C, Larimer ME. Differential alcohol expectancies based on type of alcoholic beverage consumed. Journal of Studies on Alcohol. 2010; 71:925-929.

Price SR, Hilchey CA, Darredeau C, Fulton HG, Barrett SP. Energy drink co-administration is associated with increased reported alcohol ingestion. Drug and Alcohol Review. 2010; 29:331333. [PubMed: 20565526] 
Read JP, Kahler CW, Strong DR, Colder CR. Development and preliminary validation of the young adult alcohol consequences questionnaire. Journal of Studies on Alcohol. 2006; 67:169-177. [PubMed: 16536141]

Sher KJ, Walitzer KS, Wood PK, Brent EE. Characteristics of children of alcoholics: Putative risk factors, substance use and abuse, and psychopathology. Journal of Abnormal Psychology. 1991; 10:427-448. [PubMed: 1757657]

Snipes DJ, Benotsch EG. High-risk cocktails and high-risk sex: Examining the relation between alcohol mixed with energy drink consumption, sexual behavior, and drug use in college students. Addictive Behaviors. 2013; 38:1418-1423. [PubMed: 23006245]

Stacy AW, Newcomb MD, Bentler PM. Cognitive motivation and drug use: A 9-year longitudinal study. Journal of Abnormal Psychology. 1991; 100:502-515. [PubMed: 1757664]

Thombs DL, O’Mara RJ, Tsukamoto M, Rossheim ME, Weiler RM, Merves ML, Goldberger BA. Event-level analyses of energy drink consumption and alcohol intoxication in bar patrons. Addictive Behaviors. 2010; 35:325-330. [PubMed: 19954894]

Varvil-Weld L, Marzell, Turrisi R, Mallett KA, Cleveland MJ. Examining the relationship between alcohol-energy drink risk profiles and high-risk drinking behaviors. Psychology of Addictive Behaviors. 2013; 37:1410-1416.

Woolsey C, Waigandt A, Beck NC. Athletes and energy drinks: Reported risk-taking and consequences from the combined use of alcohol and energy drinks. Journal of Applied Sport Psychology. 2010; 22:65-71. 


\section{TABLE 1}

Descriptive statistics and intercorrelations among study variables

\begin{tabular}{|c|c|c|c|}
\hline Variable & $\begin{array}{c}\text { CAB } \\
\text { quantity }\end{array}$ & $\begin{array}{c}\text { CAB } \\
\text { frequency }\end{array}$ & $\begin{array}{c}\text { Alcohol-related } \\
\text { problems }\end{array}$ \\
\hline CEOA—Sociability & $.129^{*}$ & $.123^{*}$ & $.368^{* * *}$ \\
\hline $\begin{array}{l}\text { CEOA-Tension } \\
\text { reduction }\end{array}$ & .033 & .012 & $.148^{*}$ \\
\hline CEOA_Liquid courage & $.180^{*}$ & $.154^{* *}$ & $.399^{* * *}$ \\
\hline CEOA—Sexuality & $.158^{*}$ & $.140^{*}$ & $.365^{* * *}$ \\
\hline $\begin{array}{l}\text { CEOA-Cognitive/ } \\
\text { behavioral impairment }\end{array}$ & .044 & .012 & $.361^{* * *}$ \\
\hline $\begin{array}{l}\text { CEOA—Risk and } \\
\text { aggression }\end{array}$ & $.196^{* *}$ & $.170^{* *}$ & $.448^{* * *}$ \\
\hline CEOA—Self-perception & $.263^{* * *}$ & $.219^{* * *}$ & $.297^{* * *}$ \\
\hline CEQ_-Positive effects & .036 & .035 & $.162^{* *}$ \\
\hline $\begin{array}{l}\text { CEQ_Acute negative } \\
\text { effects }\end{array}$ & -.011 & -.007 & $.190^{* * *}$ \\
\hline CEQ_-Mood effects & $.155^{* *}$ & $.132^{* *}$ & $.103^{*}$ \\
\hline $\begin{array}{l}\text { CEQ_Withdrawal } \\
\text { symptoms }\end{array}$ & $247^{* * *}$ & $.200^{* * *}$ & $.163^{* *}$ \\
\hline $\operatorname{Mean}^{a}$ & 2.94 & 1.55 & 56.92 \\
\hline Standard deviation & 4.67 & 2.20 & 8.03 \\
\hline Range & $0-24$ & $0-7$ & $48-87$ \\
\hline
\end{tabular}

Note. $\mathrm{CEOA}$, comprehensive effects of alcohol; $\mathrm{CEQ}$, caffeine expectancy questionnaire; $\mathrm{CAB}$, caffeinated alcoholic beverage; $\mathrm{CAB}$ quantity, number of $\mathrm{CAB}$ drinks per week; $\mathrm{CAB}$ frequency, days of $\mathrm{CAB}$ drinking per week.

$p<.05$

** $\quad$ < $<.01$

$* * *$

$p<.001$.

${ }^{a}$ Means and standard deviations are based on nontransformed data for CAB quantity and frequency to enhance interpretability. 
TABLE 2

Summary of hierarchical multiple regression analysis predicting CAB use quantity

\begin{tabular}{|c|c|c|c|c|c|c|}
\hline Step & Predictor & $B$ & $\beta$ & $S E(B)$ & $R^{2}$ & $\Delta R^{2}$ \\
\hline \multicolumn{7}{|c|}{ CEOA entered prior to CEQ } \\
\hline Step 1 & Gender & -.39 & -.13 & .21 & $.012^{b}$ & \\
\hline Step 2 & Alcohol use & $.03^{*}$ & .19 & .01 & .042 & $.035^{*}$ \\
\hline \multirow[t]{8}{*}{ Step 3} & CEOA & & & & .120 & $.108^{*}$ \\
\hline & Sociability & .03 & .12 & .03 & & \\
\hline & Tension reduction & -.06 & -.09 & .05 & & \\
\hline & Liquid courage & -.03 & -.08 & -.05 & & \\
\hline & Sexuality & .00 & .00 & .04 & & \\
\hline & Impairment ${ }^{\mathrm{a}}$ & $-.06^{*}$ & -.24 & .03 & & \\
\hline & Risk and aggression & .07 & .20 & .05 & & \\
\hline & Self-perception & $.17^{*}$ & .35 & .05 & & \\
\hline \multirow[t]{6}{*}{ Step 4} & CEQ & & & & .161 & $.057^{*}$ \\
\hline & Positive effects & -.00 & -.02 & .02 & & \\
\hline & Acute negative effects & -.02 & -.08 & .02 & & \\
\hline & Mood effects & -.02 & -.06 & .03 & & \\
\hline & Withdrawal symptoms & .05 & .29 & .02 & & \\
\hline & \multicolumn{6}{|c|}{ CEQ entered prior to CEOA } \\
\hline Step 1 & Gender & -.39 & -.13 & .21 & .012 & \\
\hline Step 2 & Alcohol use & $.03^{*}$ & .19 & .01 & .042 & $.035^{*}$ \\
\hline \multirow[t]{5}{*}{ Step 3} & CEQ & & & & .086 & $.062^{*}$ \\
\hline & Positive effects & -.01 & -.05 & .02 & & \\
\hline & Acute negative effects & -.01 & -.03 & .02 & & \\
\hline & Mood effects & .02 & .05 & .03 & & \\
\hline & Withdrawal symptoms & $.04^{*}$ & .24 & .02 & & \\
\hline \multirow[t]{8}{*}{ Step 4} & CEOA & & & & .161 & $.102^{*}$ \\
\hline & Sociability & .04 & .17 & .03 & & \\
\hline & Tension reduction $* * *$ Liquid courage & $-.07 * * *-.02$ & $-.11 * * *-.05$ & .05 .05 & & \\
\hline & Liquid courage & -.02 & -.05 & .05 .05 & & \\
\hline & Sexuality & .01 & .02 & .04 & & \\
\hline & Impairment $^{a}$ & $-.07^{*}$ & -.29 & .03 & & \\
\hline & Risk and aggression & .06 & .18 & .05 & & \\
\hline & Self-perception & $.17^{*}$ & .34 & .05 & & \\
\hline
\end{tabular}

Note. Gender: 1 = male, 2 = female; $\mathrm{CEOA}$, comprehensive effects of alcohol; CEQ, caffeine expectancy questionnaire; $\mathrm{CAB}$, caffeinated alcoholic beverage.

* Significant at $p<.025(.05 / 2)$ following Bonferroni correction.

${ }^{a}$ Impairment $=$ Cognitive and Behavioral Impairment. 
${ }^{b}$ The $R^{2}$ reported is the adjusted $R^{2}$. 
TABLE 3

Summary of hierarchical multiple regression analysis predicting CAB use frequency

\begin{tabular}{|c|c|c|c|c|c|c|}
\hline Step & Predictor & $\boldsymbol{B}$ & $\beta$ & $S E(B)$ & $R^{2}$ & $\Delta R^{2}$ \\
\hline \multicolumn{7}{|c|}{ CEOA entered prior to CEQ } \\
\hline Step 1 & Gender & -.18 & -.09 & .14 & $.003^{b}$ & \\
\hline Step 2 & Alcohol use & $.02 *$ & .17 & .01 & .026 & $.027^{*}$ \\
\hline \multirow[t]{8}{*}{ Step 3} & CEOA & & & & .077 & $.081^{*}$ \\
\hline & Sociability & .02 & .11 & .02 & & \\
\hline & Tension reduction & -.03 & -.07 & .03 & & \\
\hline & Liquid courage & -.02 & -.10 & .04 & & \\
\hline & Sexuality & -.01 & -.02 & .03 & & \\
\hline & Impairment $^{a}$ & $-.04^{*}$ & -.22 & .02 & & \\
\hline & Risk and aggression & .06 & .23 & .04 & & \\
\hline & Self-perception & $.10^{*}$ & .27 & .03 & & \\
\hline \multirow[t]{6}{*}{ Step 4} & CEQ & & & & .104 & .042 \\
\hline & Positive effects & .00 & .01 & .01 & & \\
\hline & Acute negative effects & -.01 & -.04 & .01 & & \\
\hline & Mood effects & -.02 & -.11 & .02 & & \\
\hline & Withdrawal symptoms & .03 & .26 & .01 & & \\
\hline & \multicolumn{6}{|c|}{ CEQ entered prior to CEOA } \\
\hline Step 1 & Gender & -.18 & -.09 & .14 & .003 & \\
\hline Step 2 & Alcohol use & $.02 *$ & .17 & .01 & .026 & $.027^{*}$ \\
\hline \multirow[t]{5}{*}{ Step 3} & CEQ & & & & .048 & .040 \\
\hline & Positive effects & -.00 & -.02 & .01 & & \\
\hline & Acute negative effects & .00 & .00 & .01 & & \\
\hline & Mood effects & -.00 & -.01 & .02 & & \\
\hline & Withdrawal symptoms & $.03^{*}$ & .21 & .01 & & \\
\hline \multirow[t]{8}{*}{ Step 4} & CEOA & & & & .104 & $.083^{*}$ \\
\hline & Sociability & .03 & .16 & .02 & & \\
\hline & Tension reduction & -.04 & -.09 & .04 & & \\
\hline & Liquid courage & -.02 & -.07 & .04 & & \\
\hline & Sexuality & -.01 & -.02 & .03 & & \\
\hline & Impairment ${ }^{a}$ & $-.05^{*}$ & -.27 & .02 & & \\
\hline & Risk and aggression & .05 & .21 & .04 & & \\
\hline & Self-perception & $.10^{*}$ & .28 & .03 & & \\
\hline
\end{tabular}

Note. Gender: 1 = male, 2 = female; $\mathrm{CEOA}$, comprehensive effects of alcohol; CEQ, caffeine expectancy questionnaire; $\mathrm{CAB}$, caffeinated alcoholic beverage.

* Significant at $p<.025(.05 / 2)$ following Bonferroni correction.

${ }^{a}$ Impairment $=$ Cognitive and Behavioral Impairment.

$b_{\text {The }} R^{2}$ reported is the adjusted $R^{2}$. 
TABLE 4

Summary of hierarchical multiple regression analysis predicting alcohol-related problems

\begin{tabular}{|c|c|c|c|c|c|c|}
\hline Step & Predictor & $\boldsymbol{B}$ & $\beta$ & $S E(B)$ & $R^{2}$ & $\Delta R^{2}$ \\
\hline \multicolumn{7}{|c|}{ CEOA entered prior to CEQ } \\
\hline Step 1 & Gender & -.74 & -.04 & 1.23 & $-.003^{b}$ & \\
\hline Step 2 & Alcohol use & $.54^{*}$ & .62 & .05 & .358 & $.363^{*}$ \\
\hline \multirow[t]{8}{*}{ Step 3} & CEOA & & & & .479 & $.138^{*}$ \\
\hline & Sociability & .17 & .11 & .12 & & \\
\hline & Tension reduction & -.39 & -.10 & .23 & & \\
\hline & Liquid courage & -.31 & -.16 & .22 & & \\
\hline & Sexuality & .08 & .03 & .19 & & \\
\hline & Impairment $^{a}$ & .10 & .07 & .11 & & \\
\hline & Risk and aggression & $.55^{*}$ & .28 & .23 & & \\
\hline & Self-perception & $.46^{*}$ & .16 & .21 & & \\
\hline \multirow[t]{5}{*}{ Step 4} & CEQ & & & & .513 & $.042^{*}$ \\
\hline & Positive effects & .14 & .12 & .07 & & \\
\hline & Acute negative effects & .16 & .11 & .08 & & \\
\hline & Mood effects & $-.46^{*}$ & -.26 & .13 & & \\
\hline & Withdrawal symptoms & .09 & .09 & .07 & & \\
\hline \multicolumn{7}{|c|}{ CEQ entered prior to CEOA } \\
\hline Step 1 & Gender & -.74 & -.04 & 1.23 & -.003 & \\
\hline Step 2 & Alcohol use & $.54^{*}$ & .62 & .05 & .358 & $.363^{*}$ \\
\hline \multirow[t]{5}{*}{ Step 3} & CEQ & & & & .409 & $.062^{*}$ \\
\hline & Positive effects & .15 & .13 & .08 & & \\
\hline & Acute negative effects & $.29^{*}$ & .20 & .08 & & \\
\hline & Mood effects & $-.33^{*}$ & -.19 & .14 & & \\
\hline & Withdrawal symptoms & .07 & .07 & .08 & & \\
\hline \multirow[t]{8}{*}{ Step 4} & CEOA & & & & .513 & $.118^{*}$ \\
\hline & Sociability & .14 & .09 & .12 & & \\
\hline & Tension reduction & -.41 & -.11 & .22 & & \\
\hline & Liquid courage & -.27 & -.14 & .22 & & \\
\hline & Sexuality & .04 & .02 & .19 & & \\
\hline & Impairment $^{a}$ & .03 & .02 & .11 & & \\
\hline & Risk and aggression & $.55^{*}$ & .28 & .23 & & \\
\hline & Self-perception & $.60^{*}$ & .21 & .21 & & \\
\hline
\end{tabular}

Note. Gender: 1 = male, 2 = female; CEOA, comprehensive effects of alcohol; CEQ, caffeine expectancy questionnaire; CAB, caffeinated alcoholic beverage.

Significant at $p<.025(.05 / 2)$ following Bonferroni correction.

$a_{\text {Impairment }}=$ Cognitive and Behavioral Impairment. 
${ }^{b}$ The $R^{2}$ reported is the adjusted $R^{2}$. 